\title{
Reform of the coroners' service in England and Wales: policy-making and politics
}

\author{
Alexandra Pitman ${ }^{1}$ \\ The Psychiatrist (2012), 36, 1-5, doi: 10.1192/pb.bp.111.036335 \\ 1 University College London, UK \\ Correspondence to Dr Alexandra \\ Pitman (a.pitman@ucl.ac.uk) \\ First received 5 Aug 2011, final revision \\ 8 Sep 2011, accepted 5 Oct 2011 \begin{abstract}
coroners' service, introducing much needed efficiencies to benefit people bereaved by suicide and other sudden deaths. Central to these reforms was the introduction of a Chief Coroner to coordinate the system and exercise wider public health responsibilities. The coalition government's proposal to abolish the Chief Coroner's office on grounds of cost, ignoring the potential efficiency gains, has delayed implementation of coronial reforms significantly. With this proposal now abandoned, ministers are expected to appoint an independent Chief Coroner in early 2012. This article describes the intended benefits of the reforms for bereaved relatives, coroners' staff, public sector budgets, and the public health, and explores the reasons behind the delays.
\end{abstract} \\ Summary The Coroners and Justice Act 2009 promised an overhaul of the
}

Declaration of interest None.
Long-debated reforms of the 800-year-old coroner system in England and Wales became law with the Coroners and Justice Act 2009, heralding improvements to the efficiency of the coroners' service, its capacity to support the bereaved people it serves, and its role in preventing future deaths. ${ }^{1}$ Clinicians had followed the legislative process closely, recognising the implications for patients and their relatives. ${ }^{2-5}$ Coronial reform was agreed to be long overdue: resources were being wasted through unnecessary bureaucracy, while funding inequities caused bottlenecks and delays. Central to the Act was the establishment of a new Chief Coroner, welcomed by the British Medical Association, the public, and all political parties for its role in streamlining the service, settling costly disputes and improving accountability. ${ }^{3}$ The intention was for the Chief Coroner to lead on a raft of reforms, effecting cost savings, efficiencies, and service improvements. Yet only months after the Act had been passed a change of government brought the announcement of a comprehensive spending review, placing most of the coroner reforms on hold. ${ }^{6}$ Under the Public Bodies Bill the Office of the Chief Coroner was marked for abolition on grounds of expense. However, this lacked any supporting cost analysis and ignored potential efficiency gains.

The average in-patient or community psychiatrist will experience the suicide of at least one patient annually, and will be well aware of the distress caused to relatives, fellow patients and team members by an inquest. ${ }^{7}$ All clinicians will appreciate the public health and mental health benefits of the coronial reforms described here and their potential for wider cost savings, including those to the National Health Service (NHS). However, these benefits should have been quantified explicitly to persuade policy makers of their value at a much earlier stage. A general principle is that responsible decision-making involves the most appropriate scientific analysis available, in this context economic evaluation, and not solely the apparent subjectivity of politicians. ${ }^{8}$ If the original Coroners and Justice Act had been based on detailed economic evaluations of each reform, including the efficiencies expected from a Chief Coroner, politics might not have interfered with its implementation. The appointment of a Chief Coroner is anticipated in early 2012, representing a delay of 2 years, with the other reforms expected to follow. This article highlights the years of consultation that preceded the Coroners and Justice Act, the range of benefits intended for bereaved relatives, coronial staff, and the public health, and the reasons for this long delay.

\section{Problems with the existing coroners' service}

In England and Wales all violent, unnatural deaths, sudden deaths of unknown cause, and deaths in custody must be referred to a coroner: an independent judicial officer who may hold an inquiry to determine who has died, and how, when and where they came by their death. Each of these inquiries is conducted within a coroner's jurisdiction, assisted by coroners' officers, who also provide a family liaison role. In 2009, 46\% of all deaths registered in England and Wales were referred to a coroner, for which inquests were opened on $31000 .^{9}$ In 2010 , the average time taken to complete an inquest was 27 weeks, with the worstperforming areas taking up to 43 weeks. ${ }^{10}$ Since the 1970 s there has been a growing awareness of the difficulties faced by relatives in relation to coroner investigations and inquests, ${ }^{11,12}$ particularly in cases of suicide. ${ }^{13,14}$ Qualitative 
research describes what can be a long and difficult process, involving frustrating administrative delays, a lack of consultation, confusing and intimidating experiences in the coroner's court, and a sometimes unanticipated verdict. $^{13-15}$

There are two reasons for these failures: a lack of accountability and devolution of funding. Despite the fact that the independence of the coronial service is crucial, particularly where investigations expose governmental failings, coroners are not accountable for decisions. Under an archaic system of devolved funding, salaries and resources are provided by the local authority, the police authority or both, resulting in pronounced geographical inequities. ${ }^{16}$ There are no service standards and no culture of mandatory training, whereas unnecessary bureaucracy contributes to backlogs. Coroners' officers struggle with heavy caseloads which limit the degree of support they can offer bereaved families. Pilot schemes involving voluntary sector organisations like the Coroners' Courts Support Service have sought to compensate for gaps in service, but the current economic climate threatens the sustainability of such arrangements. ${ }^{17}$

A 2003 independent review carried out by the Shipman Inquiry concluded that the coronial system was outdated, inconsistent and unsympathetic to families, proposing fundamental reforms led by a Chief Coroner. ${ }^{18}$ The Inquiry's report also concluded that there was insufficient medical knowledge in the coroners' system, a lack of leadership and training for coroners, and an inconsistent level of service for bereaved people. ${ }^{19}$ These recommendations prompted the Labour government to announce plans for coronial reform, published for consultation as part of the Coroners and Justice Bill 2006. Reactions to the reforms were generally positive, despite reservations about financing. Plans to allow coroners to transfer cases more flexibly demonstrated clear efforts to reduce bureaucracy. However, other opportunities for allocative efficiency had been missed, for example in ignoring the Shipman Inquiry's recommendation to introduce central funding. ${ }^{19}$ The wider costs and consequences of three key reforms are discussed below: the establishment of a Charter for the Bereaved, the creation of the post of Chief Coroner, and the introduction of a right of appeal.

\section{Key coronial reforms proposed in 2006}

\section{Charter for the Bereaved}

The Bill announced a Charter for the Bereaved setting out a range of service standards and consumer rights. ${ }^{20}$ These included material improvements to premises, for example a private room for relatives attending an inquest, as well as improved support and information for any bereaved person brought in contact with the coroner's service. Information was to be provided on coronial procedures, arrangements for viewing the body, the rationale for a post-mortem, and where and when an inquest would be held. Coroners' officers were given responsibility for providing this support, but without plans to expand their numbers, contrary to the Shipman Inquiry's specific recommendation. ${ }^{19}$ Workload reductions were anticipated through parallel reforms of the death certification process involving local medical examiners overseen by a national medical examiner. ${ }^{21}$ When piloted, this had reduced the proportion of coroner-referred deaths by $10 \%{ }^{22}$ However, the possibility remained that the Charter might raise public expectations beyond the capabilities of the service, ${ }^{23}$ offering bereaved people 'a list of laudable but unenforceable empty promises, ${ }^{24}$ echoing experiences with the National Health Service (NHS) Patients' Charter. ${ }^{25}$ By overstretching coroners' staff and hampering any uptake of training there was a risk that standards might actually fall.

\section{Chief Coroner}

A proposal to create the role of Chief Coroner presented a more affordable means of improving standards by liberating resources from wasteful bureaucracy. The intention was for a central leader to introduce consistency and transparency into the inquest service by streamlining functions, coordinating training and budgets, arbitrating over disputes, and standardising practice geographically. With a national overview of caseloads they would enhance technical efficiency (improved outcomes for a given cost) and allocative efficiency (redistributing resources to maximise outcomes), ${ }^{26}$ compensating in part for the failure to introduce central funding. These efficiencies would apply not only to the ongoing functioning of the service but to the implementation of coronial reforms. Directing this overhaul would help achieve a major objective of the Coroners' Bill enhancing the capacity of coroners' officers to provide or source support to bereaved people. Additionally, by making all coroners accountable to the Chief Coroner autonomy from the government would be preserved.

Public health responsibilities were conferred on the Chief Coroner, for which autonomy was again essential. As a national figurehead the Chief Coroner was expected to highlight coroners' recommendations on preventing future deaths, including those implicating government departments. He or she was also required to engage with regulatory bodies on prevention of deaths and provide reports on shortcomings to Parliament. Finally, there was an expectation that the Chief Coroner would ensure more consistent recording of coroners' verdicts, addressing the underreporting of suicide. ${ }^{27-29}$ A non-partisan figure such as a Chief Coroner would be best placed to redress this error, particularly where exposing any worsening of suicide rates would not be in the interests of government.

\section{Right of appeal}

The proposal to introduce a right of appeal offered relatives the opportunity to contest a range of coroner's decisions, including inquest verdicts. It was popular with bereaved people who felt it would encourage more thoughtful decision-making. ${ }^{30}$ The costs of this appeals system, estimated at $£ 2.2$ million per year, ${ }^{31}$ were to replace the expensive process of High Court applications and judicial review. However, concerns were raised about affordability and the potential for uncontainable demand. There were also wider public health ramifications for the collection of suicide statistics. A decline in suicide verdicts was a distinct possibility, either as a consequence of appeals or to avoid them. This would necessitate the revision of statistical conventions on suicide data analysis, to maintain standards 
on accuracy of monitoring. ${ }^{32}$ Although aware of the potential to increase costs, bereaved people felt that this was justified by ensuring a fair and robust system. ${ }^{30}$

\section{Consultation process}

Over the 3 years of consultation which followed the Bill's publication, coroners' staff, police, local authorities, voluntary organisations and bereaved people contributed to policy revisions. This resulted in the strengthening of an inquest's impact through requiring implicated agencies to act on its recommendations ${ }^{33,34}$ and the withdrawal of proposals threatening confidentiality of patient data. ${ }^{5}$ Media pressure ousted a reporting restrictions clause which would have protected relatives' privacy in high-profile deaths, for example in cases of apparent suicide. ${ }^{35}$ Overall stakeholder feedback praised the reforms' plans to provide training, reduce caseloads, and improve efficiency, ${ }^{30,36}$ but there were consistent concerns about affordability. Although these were acknowledged by ministers, ${ }^{37}$ at no stage were they actually addressed, and when the Act was passed in November 2009 there were already doubts about the feasibility of the reforms' implementation.

The problem faced by any interested party appraising the Bill was that it lacked an accompanying economic analysis, balancing the expected costs, savings, benefits and harms of each coronial reform. Economic evaluation is a crucial component of evidence-based policy-making, helping identify the most efficient policies. Given the wide-reaching potential impact of the reforms an appropriate analysis would have taken a societal perspective, quantifying the costs and benefits directly affecting the Ministry of Justice and those indirectly affecting bereaved people, other government departments, the voluntary sector, and society. Alternative scenarios could then be compared with each other, including comparisons with the 'do nothing' approach. Without such rational analysis it has been impossible to answer the fundamental questions in public spending: whether the additional efficiencies would balance any increased costs, and whether the potential benefits would justify any additional costs. ${ }^{38}$

\section{Current state of play}

Almost no progress has been made in implementing coronial reform since the Act became law in 2009. At that point consultation had started on the final drafting of the legislation, but coincided with the lead-up to a general election, as civil servants braced themselves for spending cuts. The outgoing Labour minister expressed fears for the reforms' implementation, reminding politicians of their cross-party support. ${ }^{31}$ By May 2010 a Conservative-Liberal Democrat coalition government had been formed and immediately conducted a spending review to address the budget deficit. Newly passed legislation was an obvious target, and civil servants were asked to review plans for coroner reforms. ${ }^{39}$ Further threats to their realisation loomed with the announcement of a 'bonfire of the quangos, ${ }^{40}$ including abolition of the office of the yet-tobe appointed Chief Coroner. ${ }^{6}$ This controversial decision, together with plans to shelve the appeals system and the office of the national medical examiner, was rationalised on grounds of expense ${ }^{6}$ but with no economic evaluation to delineate how the costs, savings and wider utilities of each position were balanced.

Pressure group INQUEST argued that this was a false economy, ${ }^{41}$ pronouncing that the reforms were 'rendered completely hollow without the driving force and national leadership of a Chief Coroner'. ${ }^{24}$ Parliament's Public Administration Select Committee agreed, arguing for a careful re-evaluation using an appropriate 'value-for-money test'. ${ }^{42}$ No economic evidence was forthcoming yet the proposals were fast-tracked for debate as part of the Public Bodies Bill 2010. Facing opposition from campaigning organisations and from House of Lords peers, who voted to protect the office of Chief Coroner, the coalition proposed a compromise: to fragment the Chief Coroner's functions and transfer them to the Ministry of Justice. ${ }^{10}$ The very basic cost estimates lacked any supporting analysis, ${ }^{43}$ and offered no evidence that the Ministry of Justice would perform these functions more cheaply or efficiently. Opposition MPs asserted that this could 'end up costing more money than it is projected to save.' ${ }^{10}$ Additionally, such an arrangement would have compromised the impartiality of the coronial system, in direct contravention of the Shipman report's recommendations on autonomy. ${ }^{19}$

In November 2011 the coalition dropped its plan to abolish the office of the Chief Coroner. Instead, minsters announced the intention to appoint a High Court Judge or Circuit Judge to the post in early 2012; 2 years after it had originally been planned. This decision appeared to have been made in anticipation of further defeats in the House of Lords, rather than on the basis of any economic analysis. The other coronial provisions in the Coroners and Justice Act were also to be implemented, bar the right of appeal against coroners' decisions and the provision for independent inspection of coroners' courts. Pressure groups continue to oppose these omissions (see INQUEST press release 'Government finally sees sense on inquest reform', 23 November 2011, www.inquest.org.uk). They argue that the right of appeal would save money on judicial reviews, reduce distress to relatives, and drive up standards, and that a lack of inspections would threaten adherence to the Charter for the Bereaved. The Charter itself also requires revision, having been amended in 2011 to reflect an unreformed coroners' service. Once the workings of the Charter and the system for complaints have been clarified in the drafting of final legislation and new rules and regulations, long-awaited service improvements might finally become apparent.

\section{Policy-making and politics}

The coronial reforms announced in 2006 reflected the value placed on consumer protection and service efficiency. ${ }^{23}$ However, the failures of the two successive governments handling them have caused major delays in realising these benefits. It is important to understand what went wrong to avoid similar wasting of resources. Both governments neglected the crucial contribution of scientific evidence in 
policy-making ${ }^{44}$ as a complement to the contribution of stakeholders $^{11,23,30,31,36,37}$ and expert opinion. ${ }^{18,19}$ Although the Labour government had taken care to counsel stakeholder opinion, it failed to conduct the necessary economic evaluations. The coalition government's response to the public deficit may indeed have been an attempt to limit wasteful bureaucracy, but without any explicit evaluations their approach risked sacrificing potential cost savings. ${ }^{31}$ For all such public sector decision-making it is crucial that consultation and parliamentary debate are informed by appropriate economic evaluation, and that the approach chosen provides a sufficiently wide perspective.

Evidence-based policy-making in relation to the 2006 Coroners and Justice Bill could have taken a very different form. Ideally, preparation would have involved setting out a clear matrix of direct and indirect costs, savings, utility gains and losses for each of its proposals, so that detailed economic evaluations could be conducted. INQUEST has highlighted the breadth in scope of such an evaluation, including costs to the NHS in managing the impact of delays on bereaved families' physical and mental health, costs to the justice system in reviewing coroners' decisions, and costs within the inquest service in investigating preventable deaths where previous failings had been ignored. ${ }^{43}$ The next stage would have involved a comparison of alternative scenarios, including a consideration of centralised funding and its impact on allocative efficiency within the coroners' service. In relation to the role of a Chief Coroner, the comparison of proposals might have sought to balance economies of scale against autonomy losses and any other direct and indirect utilities.

By performing this series of comparisons policy makers would have been able to rank their proposals by cost:utility ratios; a comprehensive, systematic and explicit process to assist in decision-making. ${ }^{38}$ Although as a general principle such rankings are only a guide to prioritisation, they reduce the chances of human subjectivity dominating over scientific evidence, as has characterised the process of coronial reform. Using this transparent process would have helped determine the contents of the Bill, inform the ensuing consultation and parliamentary stages, and influence the order of implementation. This whole approach brings rationality into decision-making over social welfare, countering vested interests and giving scientific analysis its due weight. It offers a means of translating evidence-based policy into practice, and delivering some proportion of the intended benefits for bereaved people, government agencies, and society. It remains possible for the new Chief Coroner to follow this approach when reconsidering introducing the right of appeal. Advocates for the bereaved, including clinicians, will expect him or her to factor the appropriate economic and psychological measures into such evaluations. This will balance the potential trauma and expense of judicial review for bereaved relatives, and the anticipated impact on coronial service standards, against the cost of an appeals system.

\section{Conclusion}

The coronial reforms enacted in 2009 had wide cost and utility implications. The rational and comprehensive process of economic evaluation forms part of a government's fiscal responsibilities in allocating scarce public resources, but has been lacking in decision-making over coronial reform. This has contributed to a 2-year stalemate involving much political wrangling. To prevent such situations from arising in the future, while also meeting the requirement for prudent public spending, policy makers are urged to use explicit economic evaluation in all such decision-making. Although this has been absent from coronial reforms, it is hoped that the imminent appointment of a Chief Coroner will bring about many of the benefits originally intended for bereaved people, coroners' staff, wider government departments, public health and society.

\section{About the author}

Alexandra Pitman, MRC Research Fellow, Mental Health Sciences Unit, University College London, UK.

\section{References}

1 Department for Constitutional Affairs. Coroners Service Reform: Briefing Note. TSO (The Stationery Office, 2006)

2 Dyer C. Opposition MPs object to data sharing clause in coroners bill. BMJ 2009; 338: b412.

3 Foster M. Death duties re-examined. BMA News 2009; 11 April: 10-1.

4 Luce T. Reform of the coroner system and death certification. BMJ 2007; 335: 680-1.

5 Nathanson V. Amendments to the Coroners and Justice Bill. BMJ 2009 ; 338: b895.

6 Hansard. House of Commons Written Ministerial Statements. Justice: Updating the Coroner System. 14 October 2010, Column 37WS.

7 St John-Smith P, Michael A, Davies T. Coping with a coroner's inquest: a psychiatrist's guide. Adv Psychiatr Treat 2009; 15: 7-16.

8 Brook BW, Burgman MA, Akçakaya HR, O'Grady JJ, Frankham R. Critiques of PVA ask the wrong questions: throwing the heuristic baby out with the numerical bath water. Conserv Biol 2002; 16: 262-3.

9 Ministry of Justice. Statistics on Deaths Reported to Coroners England and Wales, 2009. Ministry of Justice Statistics Bulletin, 2010.

10 Hansard. Public Bodies Bill 2010 Second Reading in the House of Commons. 12 July 2011: Column 212.

11 Davis G, Lindsey R, Seabourne G, Griffiths-Baker J. Experiencing Inquests (Home Office Research Study 241). Home Office Research, Development and Statistics Directorate, 2002.

12 Tarling R. Coroner Service Survey: A Research and Statistics Directorate Report. Home Office Research and Statistics Directorate, 1998.

13 Biddle L. Public hazards or private tragedies? An exploratory study of the effect of coroners' procedures on those bereaved by suicide. Soc Sci Med 2003; 56: 1033-45.

14 Harwood D, Hawton K, Hope T, Jacoby R. The grief experiences and needs of bereaved relatives and friends of older people dying by suicide: a descriptive and case-control study. J Affect Disord 2002; 72: 185-94.

15 BMJ. Autopsies - why families count too. 2010; 340: 481

16 Lords Hansard. Coroners and Justice Bill 2006 Second Reading in the House of Lords. 18 May 2009: Column 1204-5.

17 Charity Commission. Charities and the Economic Downturn: 4th Economic Survey of Charities. Charity Commission, 2010.

18 Luce T, Review of Coroner Services. Death Certification and Investigation in England, Wales and Northern Ireland: The Report of a Fundamental Review 2003. Cm 5831. TSO (The Stationery Office), 2003. 
19 Smith J. Third Report of The Shipman Inquiry: Death Certification and the Investigation of Deaths by Coroners. Cm 5854. TSO (The Stationery Office), 2003

20 Ministry of Justice. Draft Charter for Bereaved People Who Come into Contact with a Reformed Coroner System. TSO (The Stationery Office), 2008.

21 Department of Health. Impact Assessment of the Death Certification Sections of the Coroners and Justice Bill. Department of Health, 2008.

22 Fletcher A, Dorries C, Clayson I, Da Costa D. Improving the Death Certification Process: the Sheffield Medical Examiner Pathfinder Pilot. Department of Health, 2009.

23 Ministry of Justice. Charter for Bereaved People Who Come into Contact with a Reformed Coroner System. Revised Draft Charter and Response to 2008 Discussion Paper. TSO (The Stationery Office), 2009.

24 INQUEST. Public Bodies Bill (House of Lords): Briefing for Second Reading. INQUEST, 2010.

25 Department of Health. The Patients' Charter and You: a Charter for England. TSO (The Stationery Office), 1996.

26 Palmer S, Torgerson DJ. Definitions of efficiency. BMJ 1999; 318: 1136.

27 Hill C, Cook L. Narrative verdicts and their impact on mortality statistics in England and Wales. Health Stat Q 2011; 49: 81-100.

28 Sampson HH, Rutty GN. Under-reporting of suicide in South Yorkshire (West): a retrospective study of suicide and open verdicts returned by HM Coroner, 1992-1997. J Clin Forensic Med 1999; 6: 72-6.

29 Carroll R, Hawton K, Kapur N, Bennewith O, Gunnell D. Impact of the growing use of narrative verdicts by coroners on geographic variations in suicide: analysis of coroners' inquest data. J Public Health 2011; doi: 10.1093/pubmed/fdr091.

30 Department for Constitutional Affairs. Draft Coroners Bill: Analysis of Scrutiny by Bereaved People's Panel (held 9/11/06). TSO (The Stationery Office), 2007.

31 Ministry of Justice. Reform of the Coroner System - Next Stage: Preparing for Implementation. Consultation Paper CP/06/10. Ministry of Justice, 2010.

32 Department of Health. National Suicide Prevention Strategy for England. Department of Health Publications, 2002.

33 Department of Health. Equity and Excellence: Liberating the NHS. CM7881. Department of Health, 2010.
34 Ministry of Justice. Guidance for Coroners on Changes to Rule 43: Coroner Reports to Prevent Future Deaths. Ministry of Justice, 2008.

35 Ministry of Justice. Sensitive Reporting in Coroners' Courts: Discussion Paper. Ministry of Justice, 2008.

36 Hill R, Crouch J. Users' experience of the coroners' court. DCA Research Series 6/06. Ipsos MORI/ Department for Constitutional Affairs, 2006

37 Department for Constitutional Affairs. Coroner Reform: The Government's Draft Bill. Improving Death Investigation in England and Wales. Response to Consultation 6849/07. TSO (The Stationery Office), 2007.

38 McGuire A, Henderson J, Mooney G. The cost-benefit approach in theory. In The Economics of Health Care: An Introductory Text (eds A McGuire, J Henderson, G Mooney): 74-101. Routledge, 1988.

39 INQUEST. Press release: Coroners reform must go ahead. 1 July, 2010.

40 Wise J. Government axes a further 11 health quangos. BMJ 2010; 341: bmj.c5819.

41 INQUEST. Press release: Government plans to abolish Chief Coroners' Office condemned by voluntary sector organisations. 22 November, 2010.

42 Public Administration Select Committee. Smaller Government: Shrinking the Quango State. Public Administration Committee - Fifth Report. TSO (The Stationery Office), 2010.

43 INQUEST. Briefing on coronial reform - Second reading of the Public Bodies Bill (House of Commons). INQUEST, 2011.

44 House of Commons Science and Technology Committee. Scientific Advice, Risk and Evidence Based Policy Making: Government Response to the Committee's Seventh Report of Session 2005-06: First Special Report of Session 2006-07. HC 307. TSO (The Stationery Office), 2007.

Details in this article were correct at the time of going to press (15 November 2011). Updates are available on the UK Parliament website (http://services.parliament.uk/bills/2010-11/publicbodieshl.html) and on the INQUEST website (www.inquest.org.uk). Legislative documents on the coroners' service and coroner reform are downloadable from the Ministry of Justice website (www.justice.gov.uk), with additional publications available on the UK Parliament website (www.parliament.uk). For further information, listen to BBC Radio 4's 'Coroners under Scrutiny' (www.bbc.co.uk/iplayer/episode/b0174gly/File_on_4_Coroners_Under_ Scrutiny/), available to download until 2099 